\title{
The Dependence of the Miscibility, Stability and Compressibility of L- $\alpha$ Dioleoylphosphatidylcholine/Rutin Laurate Monolayer at the Air/Water on Temperature
}

\author{
Anlong Li ${ }^{1}$, Xiaolan Wang' ${ }^{2}$ Yu Duan², Liuya Wei ${ }^{2}$ \\ ${ }^{1}$ College of Bioscience and Technology, Weifang Medical University, Weifang, China; ${ }^{2}$ School of Pharmacy, Weifang \\ Medical University, Weifang, China
}

Correspondence to: Liuya Wei, weily@wfmc.edu.cn

Keywords: Mixed Monolayers, L- $\alpha$ Dioleoylphosphatidylcholine, Rutin Laurate, Surface Pressure-Area Isotherm, Molecular Interaction

Received: May 17, 2020 Accepted: July 21, $2020 \quad$ Published: July 24, 2020

Copyright $\odot 2020$ by author(s) and Scientific Research Publishing Inc.

This work is licensed under the Creative Commons Attribution International License (CC BY 4.0).

http://creativecommons.org/licenses/by/4.0/

\section{(c) (i) Open Access}

\section{ABSTRACT}

The miscibility, stability and compressibility of L- $\alpha$ dioleoylphosphatidylcholine/rutin laurate mixed monolayer at the air/water were investigated by Langmuir film balance to reveal the characteristic of the molecular interaction. The two components of DOPC/RL mixed monolayer were miscible throughout the mixture composition range and at three experimental temperatures of $10^{\circ} \mathrm{C}, 25^{\circ} \mathrm{C}$ and $37^{\circ} \mathrm{C}$. At all experimental conditions, RL increased the compressibility and elasticity of the DOPC monolayer. Both the temperature and the composition of the membrane affected the form of intermolecular forces in the mixed monolayer.

\section{INTRODUCTION}

Flavonoids are widely distributed in plants and exhibit a wide range of biological activities, such as anticancer [1], anti-inflammatory [2,3], anti-virus [4], anticoagulant [5, 6], anti-atherosclerosis [7], and inhibitory effects on low-density lipoprotein (LDL) oxidation [7-10]. Among others, the flavonoids are known as potent cell growth inhibitors [11], multidrug resistance modulators [12] and inhibitors of different types of kinases [13, 14]. Most of biological activities of flavonoids arise from their resistance to oxidation including scavenging free radicals, chelating transition metal ions, and protecting the lipid from peroxidization [15]. The aglucon shows more excellent anti-oxidation compared to glucoside, because the former exhibits strong lipotropy and can partition preferentially into the hydrophobic core of the bio-membrane [16]. These results were confirmed by protecting LDL [17] and the complex of carotenoids and unsaturated fatty acids from oxidation $[18,19]$ by flavonoids. Unfortunately, the hydrophilic property of flavonoids glucosides due to polyhydroxyl and saccharide groups, compresses their anti-oxidative activ- 
ity. Esterification of the hydroxyl by fatty acids is a solution to improve the hydrophobic of flavonoids. The lipophilic rutin laurate (RL) was obtained by acylation of rutin with lauric acid using the immobilized Candida antarctica lipase B (Novozym 435) as catalyst in present paper. RL was amphiphilic molecule with rutin moiety as the polar group and alkyl chain as the hydrophobic group (see in Figure 1(a)). We expect that RL will inset into bio-membrane with alkyl chain locating at the hydrophobic core. The hydrophobic interaction between the alkyl chain steadies the location of RL in the bio-membrane. Furthermore, the anti-oxidation groups keep retentive during the esterification of rutin. Thus, more prominent antioxidative activity may be expected for RL.

Biological membranes are involved in a variety of cellular functions [20, 21], such as cells adjust structure and physio-properties of their membranes (e.g. permeation, fluidity) during absorption and metabolism of pharmaceuticals. The interaction of biological membranes with partially or completely miscible biomolecules is a topic of importance, because it can be applied in broad fields, such as chemopharmacodynamic study of drug, control of medicines release, biosensors, and bioreceptor [22].

The monolayer at the air/water interface is a simple and ideal model membrane system from which the membrane property and the lipid interaction within monolayer can be easily measured under various conditions $[23,24]$. However, few papers have reported the interaction of flavonoids with lipid monolayer [20], more with the lipid bilayers [21, 22]. This is probably because flavonoids cannot spread at the air/water interface, as other conjugated aromatic molecule. However, amphiphilic flavonoid esters which were obtained by esterification could spread at air/water interface to form monolayer [20, 23].

In this paper, monolayer of $\mathrm{L}-\alpha$ dioleoylphosphatidylcholine (DOPC) was used as the model membrane to study the molecular interaction with RL, which was derived by esterification of the C4"' $\mathrm{OH}$ of rhamnose moiety with lauric acid. The characteristics such as miscibility, thermodynamic stability and compressibility of DOPC/RL mixed monolayers were investigated by Langmuir film balance to yield quantitative information on the nature of the molecular interaction, which provided valuable insights to reveal the antioxidative activity mechanism of flavonoids. The effects of temperature of the subphase on the DOPC-RL interactions were investigated.

\section{MATERIALS AND METHODS}

\subsection{Materials}

DOPC (99\%) was purchased from Sigma-Aldrich LLC. Its formula is reported in Figure 1(b). Rutin $(\geq 95 \%)$ was purchased from Beijing Biochemical Reagent Company, China, and was used as obtained. Novozym 435 (immobilized lipase B from Candida Antarctica) (enzyme activity: 10470PLU/g) was obtained from Novo-Nordisk Co., China. Lauric acid was analytical reagent and from Chengdu Kelong Chemical Plant, China. The tert-amyl alcohol was chemically pure and purchased from Beijing Chemical Plant, China. Other reagents were purchased from local reagent company.

\subsection{Preparation of RL}

RL was synthesized as follows: Novozym $435(340 \mathrm{mg})$ was added to a solution of rutin $(762 \mathrm{mg})$ and lauric acid $(1253 \mathrm{mg})$ in tert-amyl alcohol $(85 \mathrm{~mL})$. The suspension was heated to $60^{\circ} \mathrm{C}$ and stirred at 300 $\mathrm{rpm}$ with a mechanical stirrer. In order to control water content in the reaction medium, after $24 \mathrm{~h}$ of reaction, molecular sieves $4 \AA$ were added to the reactor with $100 \mathrm{~g} / \mathrm{L}$. Molecular sieves were activated by heating at $150^{\circ} \mathrm{C}$ for $24 \mathrm{~h}$ before used. Finally, the reaction was stopped and the enzyme filtered off. The solvent was removed in vacuum. The residue was chromatographed on silica gel [ethyl acetate/ethanol/water, 15:1:1 (v/v/v)] to give yellow powder. Then the powder was crystallized with methanol and pure RL was obtained.

\subsection{Film Balance Measurements}

Film balance measurements were performed using a KSV trough (KSV Instrument Ltd.) with a Wilhelmy type microbalance using a platinum plate. RL was dissolved in a mixture of chloroform and metha- 
nol with a volume ratio of 9:1. DOPC was dissolved in chloroform. The concentration of each solution was $1 \mu \mathrm{mol} / \mathrm{mL}$. Mixed DOPC/RL solutions were successively prepared with RL molar fractions $X_{\mathrm{RL}}$ of 0.167 , $0.25,0.5,0.75$ and $0.833 .100 \mu \mathrm{L}$ of the mixed solutions and the pure components were randomly spread on the aqueous subphase. Following the evaporation of the solvent $(15 \mathrm{~min})$, the monolayers were compressed at a rate of $5 \mathrm{~mm} / \mathrm{min}$. Surface-pressure vs molecular-area isotherms were recorded by film balance measurements. The experiments were performed at subphase temperatures of $37^{\circ} \mathrm{C}, 25^{\circ} \mathrm{C}$ and $10^{\circ} \mathrm{C}$.

\section{RESULTS AND DISCUSSION}

\section{1. ${ }^{1} \mathrm{H}-\mathrm{NMR}$ of RL}

${ }^{1} \mathrm{H}-\mathrm{NMR}\left(\mathrm{d}_{6}\right.$-DMSO) spectra of the final products showed the following shifts and related chemical species: $\delta 7.53\left(2 \mathrm{H}, \mathrm{m}, \mathrm{H} 2^{\prime}\right.$ and H6'), $6.78\left(1 \mathrm{H}, \mathrm{d}, \mathrm{J}=9 \mathrm{~Hz}, \mathrm{H} 5{ }^{\prime}\right), 6.28(1 \mathrm{H}, \mathrm{s}, \mathrm{H} 8), 6.11(1 \mathrm{H}, \mathrm{s}, \mathrm{H} 6), 5.32$ $(1 \mathrm{H}, \mathrm{d}, \mathrm{J}=7.4 \mathrm{~Hz}, \mathrm{H} 1$ ”), 4.66 (1H, t, J = 9 Hz, H4"'), 4.48 (1H, s, H1"'), $3.74-3.04$ (9H, m, H2” - H6”, H2”' - H5"'), $2.21-2.13\left(2 \mathrm{H}, \mathrm{m}, \mathrm{CH}_{2} \alpha\right.$, fatty chain), $1.5\left(2 \mathrm{H}, \mathrm{m}, \mathrm{CH}_{2} \beta\right.$, fatty chain), $1.25-1.13\left(16 \mathrm{H}, \mathrm{m},-\mathrm{CH}_{2^{-}}\right.$, fatty chain), $0.95\left(1 \mathrm{H}, \mathrm{t}, \mathrm{J}=7.0, \mathrm{CH}_{3}\right.$, fatty chain $), 0.85\left(1 \mathrm{H}, \mathrm{d}, \mathrm{J}=7.0, \mathrm{CH}_{3}\right.$, rhamnose $)$.

Selected ${ }^{13} \mathrm{C}-\mathrm{NMR}$ data (d6-DMSO): $\delta 177.5(\mathrm{C} 4), 174(\mathrm{C}=\mathrm{O}$ ester), $168.3(\mathrm{C} 7), 157.7$ (C9 or C2), 150.2 (C4'), 133 (C3), 122.5 (C6'), 116.7 (C5'), 77.9 (C3"), 75.3 (C5”), 74.7 (C4”'), 71.6 (C4" or C2"'), 70.9 (C2"' or C4"), 69.3 (C3"'), 67 (C5"'), 34.7 (fatty chain), 31.8 (fatty chain), 29.7 (fatty chain), 25.4 (fatty chain), 25 (fatty chain), 24.5 (fatty chain), 23.7 (fatty chain), 23.1 (fatty chain), 18.5 (fatty chain), 15.2 (fatty chain), 12.1 (fatty chain).

\subsection{Miscibility of DOPC/RL Mixed Monolayer}

Figure 1 showed the Chemical structures of RL and DOPC.

(a)
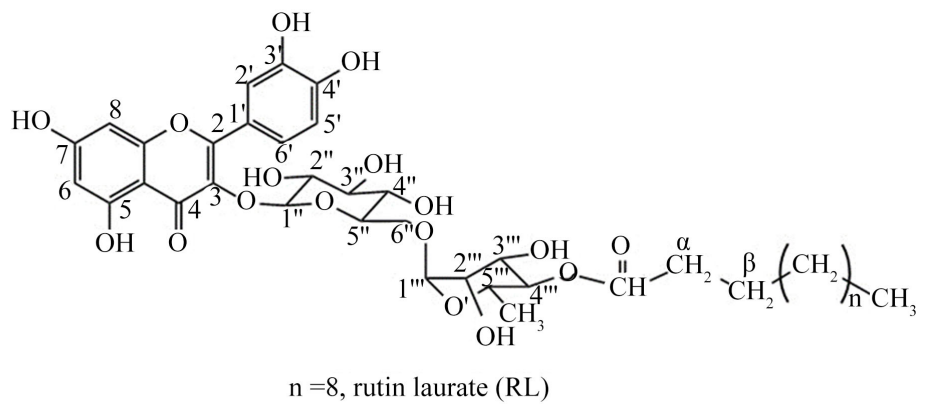

(b)

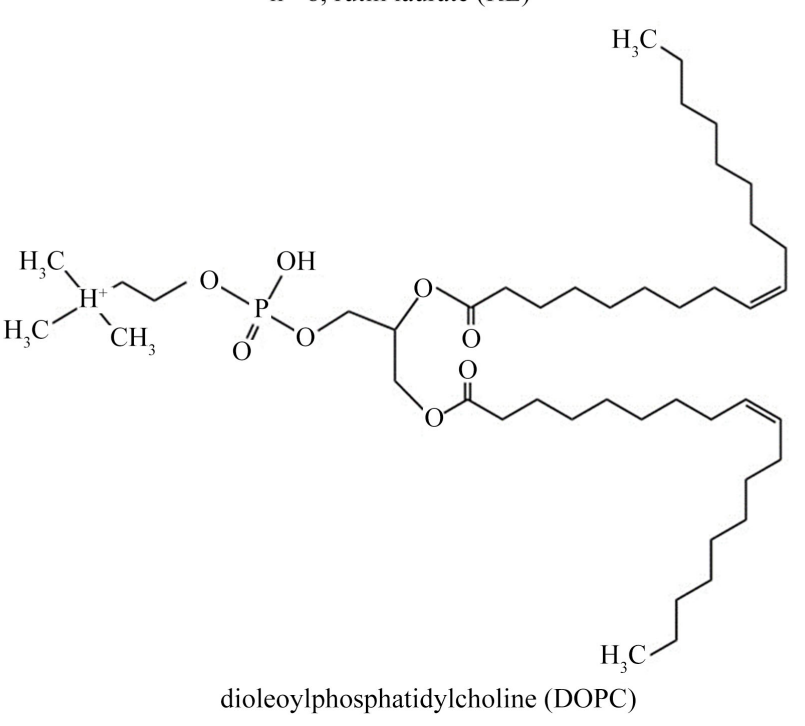

Figure 1. Chemical structures of RL (a) and DOPC (b). 
Figure 2 showed the surface pressure vs. mean molecular area $(\pi-A)$ isotherms of DOPC/RL monolayers at various mole fraction at $10^{\circ} \mathrm{C}(\mathrm{a}), 25^{\circ} \mathrm{C}(\mathrm{b})$ and $37^{\circ} \mathrm{C}(\mathrm{c})$, respectively. The $\mathrm{RL}$ mole fraction of each curve is reported in the figures.

The isotherms of pure RL in Figure 2 showed RL formed monolayer with liquid-phase at the air/water interface. The intermolecular hydrogen bonds between molecules of water and rutin leaded almost three of aromatic nucleus of rutin formed a large flat at air/water interface. Compared with the large polar groups, the alkyl chains are relatively short. Near to the collapse of the monolayers, the polar groups arranged tightly, while alkyl chains were still outside the range that was prerequisite for interaction between them and then alkyl chains were orientation disorder. Thus, the isotherm of RL monolayers with liquid-expanded phase was observed. Pure DOPC also formed the liquid-phase monolayer. The two cis-double bonds and a cone-like structure of DOPC led to the mismatch of molecular shapes and loose array of hydrophobe alky chains.

From the isotherms of DOPC/RL mixed monolayers, it was observed that at $10^{\circ} \mathrm{C}$ and $25^{\circ} \mathrm{C}$, for the mole fraction of RL $X_{\mathrm{RL}} \leq 0.5$, the surface pressures at the collapse $\left(\pi_{\text {coll }}\right)$ increased with the increase of $X_{\mathrm{RL}}$ and reached the maximum for $X_{\mathrm{RL}}=0.5$. However, for $X_{\mathrm{RL}}>0.5$, $\pi_{\text {coll }}$ was almost same at $10^{\circ} \mathrm{C}$, and decreased slightly at $25^{\circ} \mathrm{C}$. At $37^{\circ} \mathrm{C}$, the largest values of $\pi_{\text {coll }}$ of DOPC/RL mixed monolayer were observed for pure DOPC. If two components of mixed monolayer are immiscible, there are two $\pi_{\text {coll }}$ corresponding to the monolayers of two pure components. Figure 2 showed that there was a single $\pi_{\text {coll }}$ for all the mole fraction and temperatures studied. Thus, the two components are miscible throughout the mixture composition range.

The nature of the molecular interaction between the two components can be obtained quantitatively from a plot of the excess molecular area of mixing, $A_{e x}$ which is the difference in molecular area between the ideal value and the measured value, as a function of the mole fraction at a given pressure. $A_{e x}$ can be given by Equation (1).

$$
A_{e x}=A_{12}-\left(X_{1} A_{1}+X_{2} A_{2}\right)
$$

where $A_{12}$ is molecular area of the mixed monolayer; $A_{1}$ and $A_{2}$ are the molecular areas of the monolayer of component 1 and component 2 at a given surface pressure $\pi$, respectively; and $X_{1}$ and $X_{2}$ are their corresponding mole fractions. With mixtures which both components exhibit ideal miscibility or complete immiscibility, the excess area is zero and the plot of $A_{12}$ versus $X_{1}$ gives a straight line. Any deviation from the straight line indicates miscibility and non-ideality. With positive excess areas meaning greater cohesion between like molecules than the unlike components, that is, the interactions between the two components are repulsive, and negative excess areas indicating attractive forces between the unlike ones [24-26].

Figure 3 showed the variation of $A_{e x}$ with the mole fraction of RL at various surface pressures and temperatures.

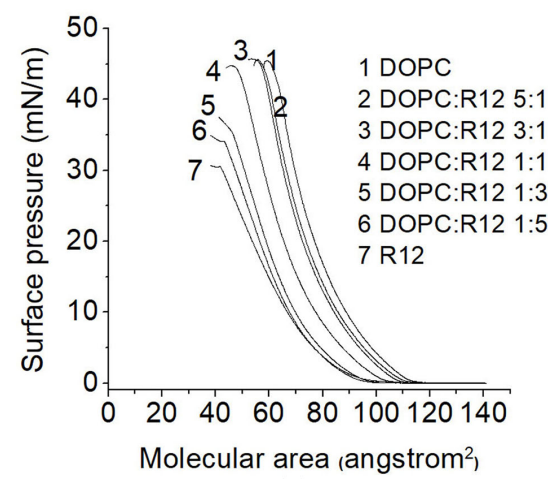

(a)

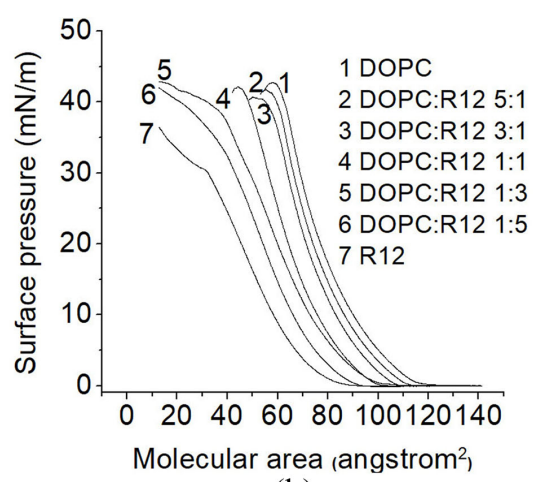

(b)

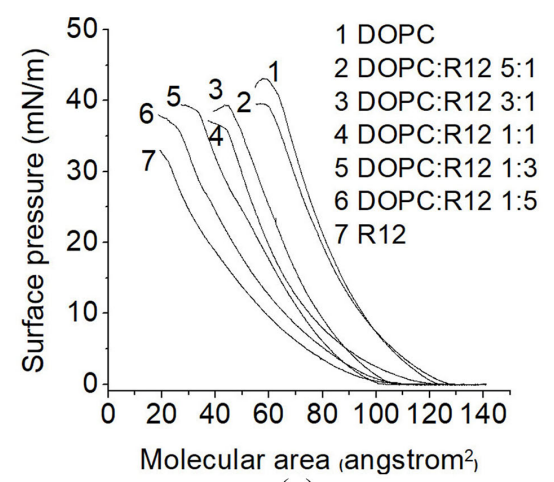

(c)

Figure 2. Surface pressure vs mean molecular area of DOPC/RL mixed monolayers at $10^{\circ} \mathrm{C}(\mathrm{a}), 25^{\circ} \mathrm{C}$ (b) and $37^{\circ} \mathrm{C}(\mathrm{c})$. 


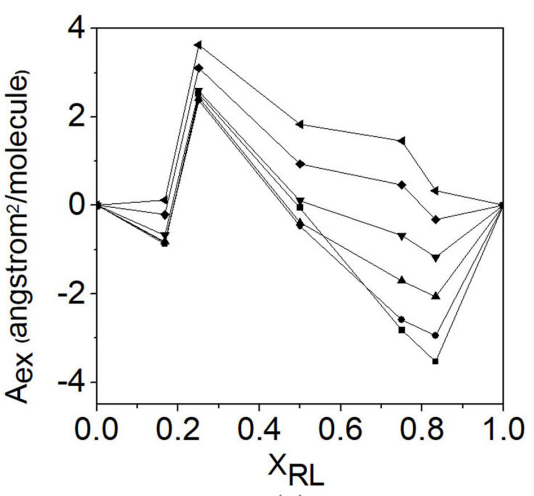

(a)

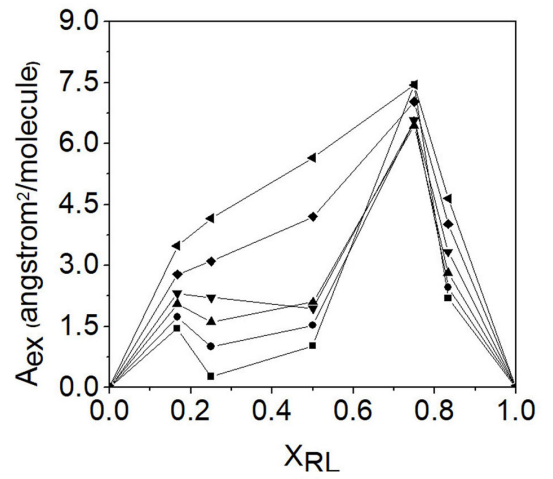

(b)

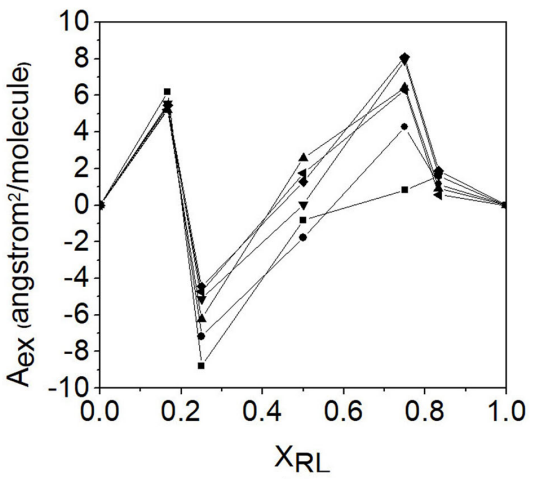

(c)

Figure 3. Excess area, Aex, as a function of the mole fraction of RL in DOPC/RL mixed monolayers at various surface pressures and temperatures. (a) $10^{\circ} \mathrm{C}$, (b) $25^{\circ} \mathrm{C}$, (3) $37^{\circ} \mathrm{C} .15 \mathrm{mN} / \mathrm{m}, \bullet 10 \mathrm{mN} / \mathrm{m}$, $\Delta 15 \mathrm{mN} / \mathrm{m}, \nabla 20 \mathrm{mN} / \mathrm{m}, \bullet 25 \mathrm{mN} / \mathrm{m}, 430 \mathrm{mN} / \mathrm{m}$.

It can be seen from Figure 3 that at $10^{\circ} \mathrm{C}$, excepting for the case of $X_{\mathrm{RL}}>0.5$ and $\pi<25 \mathrm{mN} / \mathrm{m}$, where $A_{e x}$ was negative, for all the mole fraction of RL and surface pressures studied, $A_{e x}$ was positive. At $25^{\circ} \mathrm{C}$, the values of $A_{e x}$ were all positive regardless the mole fraction of $\mathrm{RL}$ and surface pressure. At $37^{\circ} \mathrm{C}$, there was a great fluctuation of $A_{e x}$ with different $X_{\mathrm{RL}}$ and the most negative deviation of $A_{e x}$ from ideal was at the range of $0.32<X_{\mathrm{RL}}<0.35$. This difference from $\mathrm{RL}$ may be due to its shorter alkyl chain. At some mole fraction of RL and surface pressure, DOPC and RL molecular shapes mismatched, and the cohesion between RL and RL, DOPC and DOPC were greater than RL and DOPC. At high temperature, the lipid monolayers stayed in a disorder state, thus the fluctuation of $A_{e x}$ with different $X_{\mathrm{RL}}$ at $37^{\circ} \mathrm{C}$ was observed.

\subsection{Thermodynamic Stability of DOPC/RL Monolayer}

The above-mentioned interaction can be analyzed in more quantitative terms by evaluation of the excess free energy of mixing, $\Delta G_{e x}$, at a given $\pi$. This parameter is also an indicator of the type of interaction between the component $[27,28]$. For a two-component mixed monolayer at constant surface pressure $\pi$ and temperature, $\Delta G_{e x}$ can be expressed as follow:

$$
\Delta G_{e x}=\int_{0}^{\pi}\left[A_{12}-\left(X_{1} A_{1}+X_{2} A_{2}\right)\right] d \pi
$$

Negative values of $\Delta G_{e x}$ indicate the presence of attractive interaction. The existence of a minimum will indicate a mixture composition of the greatest thermodynamic stability in comparison with pure component monolayer. On the other hand, positive values suggest that the interactions between the two components are repulsive and the mixing is non-spontaneous process.

Figure 4 showed $\Delta G_{e x}$ of DOPC/RL mixed monolayers at various surface pressures at $10^{\circ} \mathrm{C}, 25^{\circ} \mathrm{C}$ and $37^{\circ} \mathrm{C}$. Only for $X_{\mathrm{RL}}>0.5$ and $\pi<25 \mathrm{mN} / \mathrm{m}, \Delta G_{e x}$ were negative. It implied that only at these conditions, the two components of DOPC/RL monolayers were miscible and mixed spontaneously. This result was consistent with the above miscibility studies. With the increase of surface pressures, $\Delta G_{e x}$ was more positive. This can be explained that high pressure resulted to short intermolecular distance, thus the repulsive force between DOPC and RL molecules was more prominent and the system was more unstable.

\subsection{Compressibility of DOPC/RL Monolayer}

The two-dimensional compressibility $C_{s}$ of a monolayer at a given molecular area of surface pressure is defined by

$$
C_{s}=(-1 / A)(d A / d \pi)
$$


where $A$ is the area per molecule at a given surface pressure $\pi . C_{s}$ can be calculated directly from the slope of the $\pi$ - $A$ isotherms. In general, $C_{s}$ depends on the state of the monolayer, being lower for more condensed films, indicating low interfacial elasticity [29-32].

Figure 5 showed the compressibility of DOPC/RL mixed monolayers versus the mole fraction of RL at $10^{\circ} \mathrm{C}, 25^{\circ} \mathrm{C}$ and $37^{\circ} \mathrm{C}$.

For all surface pressures studied, DOPC/RL mixed monolayer became more compressible as the mole fraction of RL increase. This suggested that RL made DOPC monolayer more elastic and fluid. Larger values of $C_{s}$ occurred at lower surface pressures, e.g. $\pi=5 \mathrm{mN} / \mathrm{m}$. This was because at low surface pressures, the monolayers were in their expanded state, thus their compressibility was higher as they were more fluid.

It can be summarized from the above experimental results, RL was miscible with DOPC throughout the mixture composition range and increase the compressibility and fluid of DOPC monolayer at all the experimental temperature, and at different temperatures and different molar fractions of RL, it showed different forms of intermolecular forces of RL and DOPC. At lower temperature $\left(10^{\circ} \mathrm{C}\right)$, attracting intermolecular forces occurred at higher RL mole fraction, while at higher temperature $\left(37^{\circ} \mathrm{C}\right)$ it occurred at lower RL mole fraction. At $25^{\circ} \mathrm{C}$, mutually exclusive forces occurred at all the RL mole fraction. This was most likely due to the effect of temperature on the molecular configuration of RL and DOPC.

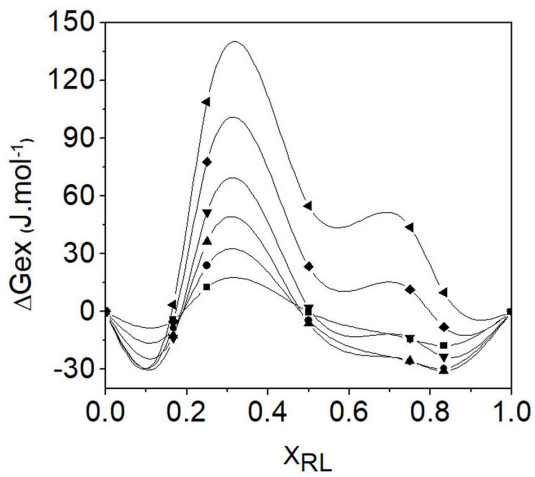

(a)

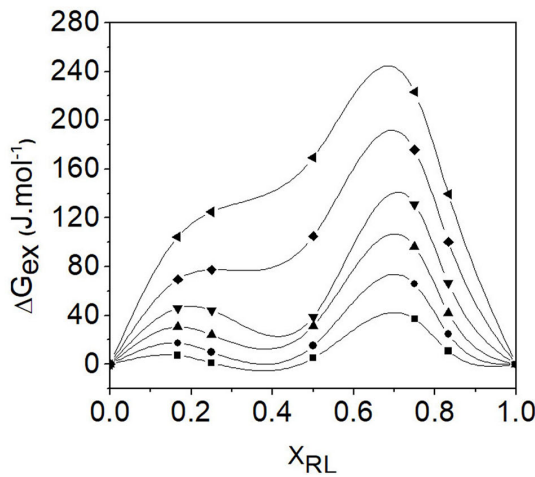

(b)

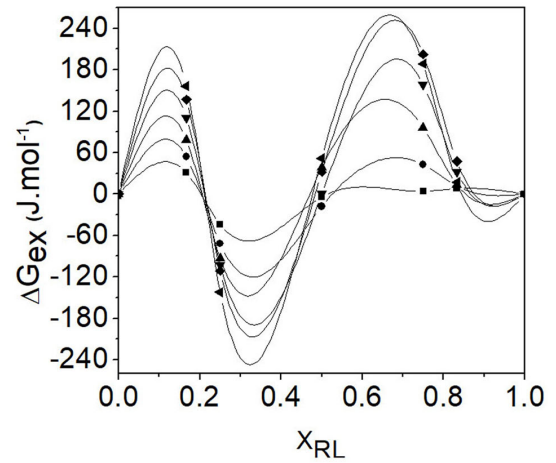

(c)

Figure 4. Excess free energy of mixing $\Delta G_{\mathrm{ex}}$ as a function of $X_{\mathrm{RS}}$ in the DOPC/RS (A) and $X_{\mathrm{RL}}$ in the DOPC/RL (B) mixed monolayers. $10^{\circ} \mathrm{C}$, (b) $25^{\circ} \mathrm{C}$, (c) $37^{\circ} \mathrm{C} . \cdot 5 \mathrm{mN} / \mathrm{m}, \bullet 10 \mathrm{mN} / \mathrm{m}, \Delta 15 \mathrm{mN} / \mathrm{m}, \nabla$ $20 \mathrm{mN} / \mathrm{m}, \bullet 25 \mathrm{mN} / \mathrm{m}, \triangleleft 30 \mathrm{mN} / \mathrm{m}$.

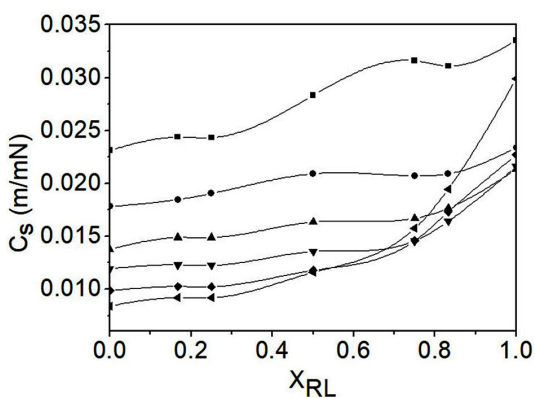

(a)

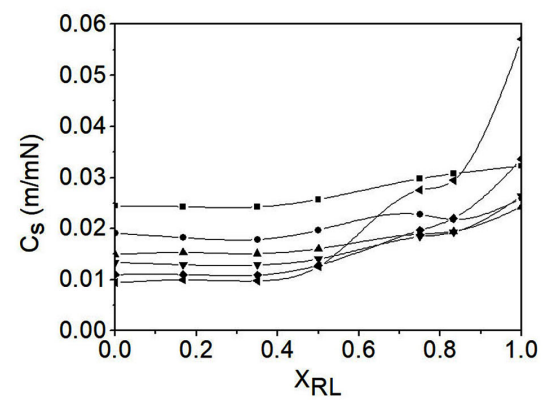

(b)

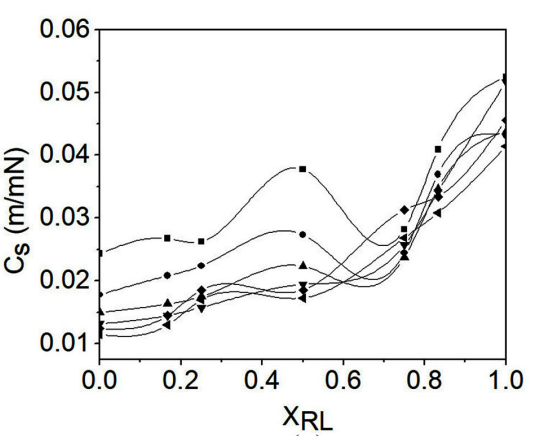

(c)

Figure 5. Surface compressibility $C_{\mathrm{s}}$ as a function of mole fraction of RL of DOPC/RL mixed monolayer at $10^{\circ} \mathrm{C}(\mathrm{a}), 25^{\circ} \mathrm{C}$ (b) and $37^{\circ} \mathrm{C}$ (c). $-5 \mathrm{mN} / \mathrm{m}, \bullet 10 \mathrm{mN} / \mathrm{m}, \Delta 15 \mathrm{mN} / \mathrm{m}, \nabla 20 \mathrm{mN} / \mathrm{m}, \bullet 25$ $\mathrm{mN} / \mathrm{m}, 430 \mathrm{mN} / \mathrm{m}$. 


\section{CONCLUSION}

The two components of DOPC/RL mixed monolayer were miscible throughout the mixture composition range and at three experimental temperatures of $10^{\circ} \mathrm{C}, 25^{\circ} \mathrm{C}$ and $37^{\circ} \mathrm{C}$. At all experimental conditions, $\mathrm{RL}$ increased the compressibility and elasticity of the DOPC monolayer. Both the temperature and the composition of the membrane affected the form of intermolecular forces in the mixed monolayer.

\section{ACKNOWLEDGEMENTS}

We thank Dacheng Wu, Zongliang Du and Ruixia Li for their helpful assistance in the experiment.

The work was supported by the National Undergraduate Training Program for Innovation and Entrepreneurship (201910438015) and Natural Science Foundation of Shandong Province [ZR2016HM47].

\section{CONFLICTS OF INTEREST}

The authors declare no conflicts of interest regarding the publication of this paper.

\section{REFERENCES}

1. Hazafa, A., Rehman, K.U., Jahan, N. and Jabeen, Z. (2020) The Role of Polyphenol (Flavonoids) Compounds in the Treatment of Cancer Cells. Nutrition and Cancer, 72, 386-397.

https://doi.org/10.1080/01635581.2019.1637006

2. Zhang, M.R., Jiang, K., Yang, J.L. and Shi, Y.P. (2019) Flavonoids as Key Bioactive Components of Oxytropis Falcata Bunge, a Traditional Anti-Inflammatory and Analgesic Tibetan Medicine. Natural Product Research, 27, 1-18. https://doi.org/10.1080/14786419.2019.1574786

3. Ginwala, R., Bhavsar, R., Chigbu, D.I., Jain, P. and Khan, Z.K. (2019) Potential Role of Flavonoids in Treating Chronic Inflammatory Diseases with a Special Focus on the Anti-Inflammatory Activity of Apigenin. Antioxidants (Basel), 8, E35. https://doi.org/10.3390/antiox8020035

4. Ortega, J.T., Serrano, M.L., Suarez, A.I., Baptista, J., Pujol, F.H., Cavallaro, L.V., Campos, H.R. and Rangel, H.R. (2019) Antiviral Activity of Flavonoids Present in Aerial Parts of Marcetia Taxifolia against Hepatitis B Virus, Poliovirus, and Herpes Simplex Virus in Vitro. EXCLI JOURNAL, 18, 1037-1048.

5. Correia-da-Silva, M., Sousa, E., Duarte, B., Marques, F., Carvalho, F., Cunha-Ribeiro, L.M. and Pinto, M.M. (2011) Polysulfated Xanthones: Multipathway Development of a New Generation of Dual Anticoagulant/Antiplatelet Agents. Journal of Medicinal Chemistry, 54, 5373-5384. https://doi.org/10.1021/jm2006589

6. Bijak, M., Ponczek, M.B. and Nowak, P. (2014) Polyphenol Compounds Belonging to Flavonoids Inhibit Activity of Coagulation Factor X. International Journal of Biological Macromolecules, 65, 129-135.

https://doi.org/10.1016/j.ijbiomac.2014.01.023

7. Dong, P., Pan, L., Zhang, X., Zhang, W., Wang, X., Jiang, M., Chen, Y., Duan, Y., Wu, H., Xu, Y., Zhang, P. and Zhu, Y. (2017) Hawthorn (Crataegus pinnatifida Bunge) Leave Flavonoids Attenuate Atherosclerosis Development in apoE Knock-Out Mice. Journal of Ethnopharmacology, 198, 479-488.

https://doi.org/10.1016/j.jep.2017.01.040

8. Joo, S.J., Park, H.J., Park, J.H., Cho, J.G., Kang, J.H., Jeong, T.S., Kang, H.C., Lee, D.Y., Kim, H.S., Byun, S.Y. and Baek, N.I. (2014) Flavonoids from Machilus Japonica Stems and Their Inhibitory Effects on LDL Oxidation. International Journal of Molecular Sciences, 15, 16418-16429. https://doi.org/10.3390/ijms150916418

9. Huh, G.W., Park, J.H., Kang, J.H., Jeong, T.S., Kang, H.C. and Baek, N.I. (2014) Flavonoids from Lindera Glauca Blume as Low-Density Lipoprotein Oxidation Inhibitors. Natural Product Research, 28, 831-834. https://doi.org/10.1080/14786419.2013.879583

10. Lee, D.Y., Shrestha, S., Seo, W.D., Lee, M.H., Jeong, T.S., Cho, J.H., Song, Y. C., Kang, H.W., Rho, Y.D. and 
Baek, N.I. (2012) Structural and Quantitative Analysis of Antioxidant and Low-Density Lipoprotein-Antioxidant Flavonoids from the Grains of Sugary Rice. Journal of Medicinal Food, 15, 399-405. https://doi.org/10.1089/jmf.2011.1905

11. Neves, A.R., Correia-da-Silva, M., Silva, P.M.A., Ribeiro, D., Sousa, E., Bousbaa, H. and Pinto, M. (2018) Synthesis of New Glycosylated Flavonoids with Inhibitory Activity on Cell Growth. Molecules, 23, E1093. https://doi.org/10.3390/molecules23051093

12. Mohana, S., Ganesan, M., Rajendra Prasad, N., Ananthakrishnan, D. and Velmurugan, D. (2018) Flavonoids Modulate Multidrug Resistance through WNT Signaling in P-Glycoprotein Overexpressing Cell Lines. BMC Cancer, 18, 1168. https://doi.org/10.1186/s12885-018-5103-1

13. Gu, C., Stashko, M.A., Puhl-Rubio, A.C., Chakraborty, M., Chakraborty, A., Frye, S.V., Pearce, K.H., Wang, X., Shears, S.B. and Wang, H. (2019) Inhibition of Inositol Polyphosphate Kinases by Quercetin and Related Flavonoids: A Structure-Activity Analysis. Journal of Medicinal Chemistry, 62, 1443-1454. https://doi.org/10.1021/acs.jmedchem.8b01593

14. Dong, H., Lin, W., Wu, J. and Chen, T. (2010) Flavonoids Activate Pregnane X Receptor-Mediated CYP3A4 Gene Expression by Inhibiting Cyclin-Dependent Kinases in HepG2 Liver Carcinoma Cells. BMC Biochemistry, 11, 23. https://doi.org/10.1186/1471-2091-11-23

15. Zhang, H., Li, X., Wu, K., Wang, M., Liu, P., Wang, X. and Deng, R. (2016) Antioxidant Activities and Chemical Constituents of Flavonoids from the Flower of Paeonia ostii. Molecules, 22, E5. https://doi.org/10.3390/molecules22010005

16. Song, Q., Cao, W.-L., Jiang, H., Zhang, A.-H. and Meng, X.-C. (2016) $\mathrm{H}_{2} \mathrm{O}_{2}$ Improves Quality of Radix Scutellariae through Anti-Oxidant Effect. Pharmacognosy Magazine, 12, 84-90. https://doi.org/10.4103/0973-1296.176063

17. Wu, C.H., Lin, J.A., Hsieh, W.C. and Yen, G.C. (2009) Low-Density-Lipoprotein (LDL)-Bound Flavonoids Increase the Resistance of LDL to Oxidation and Glycation under Pathophysiological Concentrations of Glucose in Vitro. Journal of Agricultural and Food Chemistry, 57, 5058-5064. https://doi.org/10.1021/jf9001445

18. Han, R.M., Zhang, J.P. and Skibsted, L.H. (2012) Reaction Dynamics of Flavonoids and Carotenoids as Antioxidants. Molecules, 17, 2140-2160. https://doi.org/10.3390/molecules17022140

19. Battilana, P., Ornstein, K., Minehira, K., Schwarz, J.M., Acheson, K., Schneiter, P., Burri, J., Jequier, E. and Tappy, L. (2001) Mechanisms of Action of Beta-Glucan in Postprandial Glucose Metabolism in Healthy Men. European Journal of Clinical Nutrition, 55, 327-333. https://doi.org/10.1038/sj.ejcn.1601160

20. Viskupicova, J., Strosova, M., Sturdik, E. and Horakova, L. (2009) Modulating Effect of Flavonoids and Their Derivatives on Sarcoplasmic Reticulum Ca2+-ATPase Oxidized by Hypochloric Acid and Peroxynitrite. Neuroendocrinology Letters, 30, 148-151.

21. Gao, Q., Liu, H., Ding, Q., Du, J., Liu, C., Yang, W., Shen, P. and Yang, C. (2018) A Red-Emitting Indolium Fluorescence Probe for Membranes-Flavonoids Interactions. Luminescence, 33, 582-587. https://doi.org/10.1002/bio.3449

22. Efimova, S.S., Schagina, L.V. and Ostroumova, O.S. (2017) Dipole-Modifying Effect of Styrylpyridinium Dyes and Flavonoids on the Model Membranes of Different Lipid Compositions. Tsitologiia, 59, 229-235. https://doi.org/10.1134/S1990519X17040058

23. Duan, Y., and Wang, X.L. (2014) Monolayers of Three Amphiphilic Esters of Rutin at the Air-Water Interface. Journal of Chemical and Pharmaceutical Research, 6, 305-311.

24. Flasinski, M., Gawrys, M., Broniatowski, M. and Wydro, P. (2016) Studies on the Interactions between Parabens and Lipid Membrane Components in Monolayers at the Air/Aqueous Solution Interface. Biochimica et Biophysica Acta, 1858, 836-844. https://doi.org/10.1016/j.bbamem.2016.01.002 
25. Chen, K.B., Chang, C.H., Yang, Y.M. and Maa, J.R. (2000) On the Interaction of Dipalmitoyl Phosphatidylcholine with Normal Long-Chain Alcohols in a Mixed Monolayer: A Thermodynamic Study. Colloids and Surfaces $A$, 170, 199-208. https://doi.org/10.1016/S0927-7757(00)00562-8

26. Chou, T.H., Chen, S.C. and Chu, I.M. (2003) Effect of Composition on the Stability of Liposomal Irinotecan Prepared by a pH Gradient Method. Journal of Bioscience and Bioengineering, 95, 405-408. https://doi.org/10.1016/S1389-1723(03)80076-2

27. Pagano, R.E. and Gershfeld, N.L. (1972) Physical Chemistry of Lipid Films at the Air-Water Interface. II. Binary Lipid Mixtures. The Principles Governing Miscibility of Lipids in Surfaces. The Journal of Physical Chemistry, 76, 1238-1243. https://doi.org/10.1021/j100653a002

28. Chou, T.H. and Chang, C.H. (2000) Thermodynamic Behavior and Relaxation Processes of Mixed DPPC/Cholesterol Monolayers at the Air/Water Interface. Colloids and Surfaces B, 17, 71-79. https://doi.org/10.1016/S0927-7765(99)00102-2

29. Ali, S., Smaby, J.M., Momsen, M.M., Brockman, H.L. and Brown, R.E. (1998) Acyl Chain-Length Asymmetry Alters the Interfacial Elastic Interactions of Phosphatidylcholines. Biophysical Journal, 74, 338-348. https://doi.org/10.1016/S0006-3495(98)77791-4

30. Smaby, J.M., Brockman, H.L. and Brown, R.E. (1994) Cholesterol's Interfacial Interactions with Sphingomyelins and Phosphatidylcholines: Hydrocarbon Chain Structure Determines the Magnitude of Condensation. Biochemistry, 33, 9135-9142. https://doi.org/10.1021/bi00197a016

31. Smaby, J.M., Momsen, M.M., Brockman, H.L. and Brown, R.E. (1997) Phosphatidylcholine Acyl Unsaturation Modulates the Decrease in Interfacial Elasticity Induced by Cholesterol. Biophysical Journal, 73, 1492-1505. https://doi.org/10.1016/S0006-3495(97)78181-5

32. Ali, S., Smaby, J.M., Brockman, H.L. and Brown, R.E. (1994) Cholesterol's Interfacial Interactions with Galactosylceramides. Biochemistry, 33, 2900-2906. https://doi.org/10.1021/bi00176a020 